\title{
Incidencias de las nuevas tecnologías en el Derecho Internacional Privado
}

\section{POR LUCIANA B. SCOTTI(*)}

Sumario: I. Introducción.- II. El impacto de las nuevas tecnologías en el Derecho Internacional Privado.- III. El Derecho Internacional Privado para la regulación de Internet icontinuidad o cambio de paradigma?- IV. Los problemas clásicos del DIPr: la jurisdicción competente y el derecho aplicable.- V. Mecanismos alternativos para la solución de controversias en Internet.- VI. Beneficios y desafíos de las TIC en el sector de la cooperación jurídica internacional.- VII. A modo de colofón.- VIII. Bibliografía.

Resumen: varias de las características de Internet, y principalmente su internacionalidad, nos llevan, como corolario, a definirla como un espacio esencialmente extraterritorial. Nos encontramos ante la misma extraterritorialidad que es inherente a la existencia y necesidad del Derecho Internacional Privado, que lo caracteriza y le concede su razón de ser. Sin embargo, la ubicuidad de Internet conlleva numerosos problemas jurídicos, en particular en materia de conflicto de leyes y de jurisdicciones, propios de nuestra disciplina. De allí, la íntima relación entre Derecho Internacional Privado e Internet y las nuevas tecnologías en general. En este sentido, estas irrumpen en los tres sectores de nuestra disciplina: la jurisdicción competente, el derecho aplicable y la cooperación jurídica

(*) Abogada (Medalla de oro, Universidad de Buenos Aires, UBA). Magister en Relaciones Internacionales, Universidad de Buenos Aires (UBA). Doctora de la Universidad de Buenos Aires, área Derecho Internacional. Diploma de Posdoctorado, Facultad de Derecho, Universidad de Buenos Aires (UBA). Prof. Adjunta regular Derecho Internacional Privado y Derecho de la Integración, Facultad de Derecho, Universidad de Buenos Aires (UBA). Investigadora Categoría I (Ministerio de Educación). Vicedirectora y Miembro Permanente del Instituto de Investigaciones Jurídicas y Sociales "Dr. Ambrosio L. Gioja". Directora de Proyectos UBACyT. 
internacional, ya sea para complejizar o para facilitar sus soluciones, según el caso. Precisamente, en este trabajo procuramos compartir algunos aportes a la comprensión de las incidencias de las nuevas tecnologías, y en especial de Internet, en tales ámbitos.

Palabras claves: tecnologías de la comunicación y de la información (TIC) Internet - extraterritorialidad - Derecho Internacional Privado (DIPr)

\section{Incidences des nouvelles technologies en droit international privé}

Résumé: plusieurs des caractéristiques de l'Internet, et principalement son caractère international, nous conduisent, en corollaire, à définir Internet comme un espace essentiellement extraterritorial. Nous sommes confrontés à la même extraterritorialité inhérente à l'existence et à la nécessité du droit international privé, qui le caractérise et lui donne sa raison d'être. Cependant, l'omniprésence d'Internet entraîne de nombreux problèmes juridiques, notamment en matière de conflits de lois et de juridictions, typiques de notre discipline. De là, la relation intime entre le droit international privé et Internet et les nouvelles technologies en général. En ce sens, elles pénètrent dans les trois secteurs de notre discipline: juridiction compétente, droit applicable et coopération juridique internationale, soit pour complexifier soit pour faciliter leurs solutions, selon le cas. Précisément, dans ce travail, nous essayons de partager quelques contributions à la compréhension de l'incidence des nouvelles technologies, et en particulier Internet, dans ces domaines.

Mots-clés: technologies de l'information et de la communication (TIC) - Internet - extraterritorialité - droit international privé

\section{Introducción}

Habitamos en una "sociedad de la información", en donde el activo económico principal y el bien transable por excelencia en el mercado es la propia información, en particular, en formato inmaterial, digital, independiente de las fronteras estatales. Las (nuevas) tecnologías de la comunicación y de la información (TIC) han llegado para formar parte de nuestras vidas cotidianas. La nave insignia de las TIC, sin dudas, es Internet, que ha cambiado la forma de comunicarnos, de negociar, de comprar, de educarnos y de buscar un espacio de recreación (Smith, 2000, p. 247).

En líneas generales, los problemas jurídicos surgidos con motivo de la aparición de Internet tienen relación con el conflicto entre su naturaleza deslocalizada y la índole territorial de ciertas normas que se basan en la noción de "lugar" (lugar de celebración de un contrato, lugar de ejecución o cumplimiento de un contrato, lugar del establecimiento de una de las partes, lugar de su domicilio o residencia 
habitual, lugar de comisión del delito, lugar de producción del daño, etcétera). O bien, se vinculan al conflicto entre la naturaleza inmaterial de Internet y las normas que exigen o presuponen soporte papel (Draetta, 2005, p. 52).

En efecto, esta red de redes ha erosionado las fronteras geográficas. De allí, la enorme dificultad que enfrentan los Estados para regular de modo independiente este fenómeno. Vale recordar que, respecto de la naturaleza jurídica de Internet, para algunos solo constituye un medio de transmisión, de comunicación novedoso, que en consecuencia no representa un cambio sustancial en relación con otros medios tradicionales. Para otros, en cambio, Internet es un exponente de transformación social, que conmueve los cimientos clásicos sobre los que se edificaron los ordenamientos jurídicos. Ante estas posiciones antagónicas, surgen dos grupos, tal como afirma Lorenzetti (2001): una posición “ontológica", según la cual estamos ante un mundo nuevo que demanda un derecho diferente, y la otra, "instrumental", que traslada sin más las reglas existentes mediante el principio de analogía. Ambas corrientes difieren sustancialmente respecto del problema de la regulación de Internet (p. 37).

Ahora bien, la diferenciación entre un mundo real y un mundo virtual, que transcurren en paralelo, sin vinculación, es hoy más que nunca un mito. Real y virtual no son antónimos, al punto que se suele hablar de una "realidad virtual", que la propia Real Academia Española define como "representación de escenas o imágenes de objetos, producida por un sistema informático, que da la sensación de su existencia real".

Sin embargo, en el plano de lo jurídico, existen algunos rasgos que aún nos permiten distinguir los mercados tradicionales de los mercados electrónicos o virtuales. Siguiendo al Prof. Santos Belandro (2013) podemos mencionar los siguientes caracteres distintivos: la transnacionalidad del espacio virtual; la instantaneidad de las transacciones; el anonimato de los operadores; y la digitalización de los productos.

Varias de estas características de Internet, y principalmente su internacionalidad, su alcance planetario, nos llevan, como corolario, a definir a Internet como un espacio esencialmente extraterritorial.

Nos referimos a esa misma extraterritorialidad que es inherente a la existencia y necesidad del Derecho Internacional Privado (DIPr), que lo caracteriza y le concede su razón de ser.

No obstante, la ubicuidad de Internet conlleva numerosos dilemas jurídicos, en particular en materia de conflicto de leyes y de jurisdicciones, propios de nuestra disciplina. 
De allí, la íntima relación entre Derecho Internacional Privado e Internet y las nuevas tecnologías en general. En este sentido, estas irrumpen en los tres sectores de la disciplina: la jurisdicción competente, el derecho aplicable y la cooperación jurídica internacional, ya sea para complejizar o para facilitar sus soluciones, según el caso, como veremos más adelante.

\section{El impacto de las nuevas tecnologías en el Derecho Internacional Privado}

Tal como manifiesta Pamboukis (2008), es necesario comprender los cambios que la revolución comunicacional, y sobre todo Internet, han producido. La gobernanza internacional tradicional se encuentra en plena revolución y ello amerita reflexionar: ¿surgen nuevos problemas? ¿Deben ser regulados? ¿Cómo y por quién? (p. 285).

Muchas son las problemáticas de índole jurídica que suscita este fenómeno apasionante. Entre ellas, podemos mencionar las relativas a la publicidad en Internet, la ley aplicable al contrato y al documento electrónico, la jurisdicción competente, la validez de la firma digital y del dinero electrónico, los delitos informáticos, la falta de seguridad en la red, los alcances de la libertad de expresión en el ciberespacio, la protección de los datos personales y las consecuencias de la violación al derecho a la intimidad, la transgresión de los derechos de los consumidores y usuarios, la piratería (violación al derecho de propiedad intelectual), el pago de impuestos y aranceles en el comercio electrónico y las consiguientes infracciones impositivas, la vulneración de principios fundacionales del Derecho Laboral a través del llamado teletrabajo, la responsabilidad extracontractual, la pornografía infantil.

Internet facilita el estallido de verdaderos conflictos transatlánticos, que oponen valores culturales fundamentales como la libertad de expresión y la prohibición de incitación del odio racial, o concepciones divergentes sobre la protección debida a la propiedad intelectual. Necesariamente, arribar a una solución u otra es una definición política e ideológica, ya sea a la hora de legislar, ya sea a la hora de dictar una sentencia (Muir Watt, 2004).

Para ilustrar estas palabras, podemos recordar el célebre asunto "Yahoo Inc. $v$. La Ligue Contre Le Racisme et L'Antisemitisme". Dos organizaciones civiles de origen francés: Defendants La Ligue contre le Racisme et l 'Antisemitisme ("LICRA") y L'Union des Etudiants Juifs de France decidieron entablar una demanda civil en el Tribunal de Grande Instance de París en contra de "Yahoo", ya que se encontró propaganda, memorabilia y artefactos nazis que esta empresa ofrecía en su sitio de subastas infringiendo las leyes de libertad de expresión en Francia. 
Este tribunal libró una orden judicial solicitando a "Yahoo" que eliminara todo acceso a los materiales y propaganda y le impuso una multa por la cantidad de cien mil euros por cada día que pasara y que no cumpliese con dicha orden. "Yahoo" interpuso una queja ante un Tribunal del Estado de California, solicitando una resolución declaratoria (declaratory judgement) a fin de que la orden del tribunal francés no fuera reconocida, ni ejecutada y quedara sin efecto legal alguno en los Estados Unidos.

La Corte del Estado de California resolvió que la orden del tribunal francés violaba los derechos de la Primera Enmienda de la Constitución americana y decidió dejar sin efecto la orden francesa en territorio americano.

En este caso, se pudo vislumbrar la aplicación de la noción de orden público internacional por parte de la justicia francesa para impedir que en su territorio se difundiera cierto tipo de información a través de Internet, en resguardo de principios fundamentales.

Frente a este argumento se sostiene que, con independencia de los países desde los que se puede acceder a una página web, son aplicables las leyes del lugar de la sede de la empresa. En este sentido, en el caso "Yahoo", las compañías norteamericanas sostuvieron que ningún tribunal ni autoridad extranjera podría limitar las actividades (en el caso, venta por internet de material pro nazi) de firmas con sede en los Estados Unidos. Sin embargo, desde la posición opuesta, cuando los grandes portales de Internet sitos en EE.UU. ofrecen sus productos para su adquisición en otros países, están obligados a respetar las leyes estatales que rigen el entramado de derecho público de la economía de los mercados nacionales en los que operan y las leyes del país desde el que se puede comprar el producto, país en cuyo mercado se oferta el producto, de modo que deben sujetarse a todas las leyes de todos los países en cuyos mercados se opere. Si se opera a escala mundial, se deben respetar todas las normas de derecho público de la economía de cada ley estatal (Worldwide Effect) (Calvo Caravaca, 2001, p. 147).

Asimismo, podemos traer a colación otro caso que alcanzó un alto grado de notoriedad pública. Nos referimos al affaire del médico personal del fallecido presidente de Francia François Mitterand, el Dr. Claude Gubler, quien publicó un libro, Le grand secret, donde aportaba cuestiones íntimas del presidente (una de ellas fue que el jefe de Estado no se hallaba en condiciones de ejercer el poder debido a un cáncer prostático, algo que se le ocultó a la ciudadanía con informes médicos falsos o parciales), ante lo cual la familia del mandatario solicitó y obtuvo de la Justicia la prohibición de circulación de la obra y la requisa de los libros. La medida resultó ineficaz aun cuando, en principio, fue aceptada por el médico de cabecera; ya que bastó que un ciudadano francés, Pascal Barbiaud, escaneara la obra completa en un cibercafé de Besançon y la incorporara a Internet para que circulara 
libremente por el mundo e incluso en la propia Francia, volviendo inconducente cualquier medida judicial que quisiera atacar esta libertad. El sitio del cual partió la difusión fue luego clausurado, pero la obra igual continuó circulando por todo el mundo (Santos Belandro, 2013).

Ante este tipo de sucesos, ¿quién es el encargado de regular el ciberespacio y en todo caso, cómo debe o puede hacerlo? Cualquier respuesta que se pueda aproximar está directamente relacionada con el alcance de un valor tan esencial, como la libertad.

Así lo expresa Muir Watt (2004):

Les débats relatifs à la régulation étatique du cyberespace font apparaître en effet un puissant argument 'libertaire', selon lequel l'Internet serait un milieu naturel de libre circulation des idées et des informations dans lequel aucune contrainte étatique destinée à en limiter la diffusion n'aurait de légitimité (p. 245).

En efecto, Internet es un instrumento que puede maximizar y hasta exacerbar la autonomía individual, pero también puede servir como un mecanismo de control y vigilancia permanente. Toda regulación debe buscar un equilibrio entre tales extremos.

A la hora de poner cierto orden en el ciberespacio, el Derecho Internacional Privado puede jugar un papel muy destacado.

\section{El Derecho Internacional Privado para la regulación de Internet ¿continuidad o cambio de paradigma?}

Calvo Caravaca y Carrascosa González (2001b) explican de un modo esclarecedor el rol que desempeña el Derecho Internacional Privado en la regulación de Internet:

La irrupción de Internet en el mundo del Derecho repercute en todas las ramas jurídicas, pero especial y fundamentalmente en el Derecho internacional privado. Internet representa el modo más depurado, hasta ahora, de mundializar y globalizar las situaciones privadas: incrementa el número y variedad de situaciones privadas internacionales. Ello hace del Derecho internacional privado el protagonista principal del impacto del Internet en el mundo jurídico (p. 147).

En efecto, tal como destaca Burnstein (1995), las cuestiones legales más espinosas que plantea el ciberespacio corresponden al Derecho Internacional Privado: ¿qué tribunales serán competentes y qué ley aplicarán a los diversos litigios 
que pueden surgir en Internet? (p. 87). Por ello, el interrogante que podemos plantearnos es el siguiente: $i$ es realmente necesario generar un "derecho de Internet" o un "derecho del comercio electrónico", distinto, autónomo del Derecho Internacional Privado, y en especial del Derecho Comercial Internacional.

En realidad, lejos de amenazar la existencia del Derecho Internacional Privado, Internet fortalece su necesidad y su función principal: garantizar la protección de los individuos en todas aquellas relaciones jurídicas privadas, que presenten elementos extranjeros. En tanto existan divergencias entre los sistemas jurídicos estatales, no podrán desaparecer las reglas de Derecho Internacional Privado. Sería necesario uniformar todo el derecho y dotar a los jueces de una competencia universal, lo cual es poco probable, dadas las diversas tradiciones jurídicas (Fauvarque - Cosson, 2001, p. 3).

Ante este panorama, el interrogante gira en torno a la necesidad $-\mathrm{o}$ no- de una suerte de metamorfosis o cambio de paradigma del Derecho Internacional Privado ante los nuevos escenarios.

Nuestra disciplina nació y se desarrolló con miras a regular espacios con fronteras físicas, que la geografía nos permitía delimitar perfectamente. Las innovaciones tecnológicas, y en especial, Internet, al menos a simple vista, amenaza al paradigma clásico del Derecho Internacional Privado.

No podemos negar, en efecto, que el tradicional recurso de localizar territorialmente las relaciones jurídicas a fin de regularlas por una determinada legislación nacional ha dejado de ser una tarea sencilla ante el advenimiento de un espacio, de un medio, de un ámbito no sujeto a reglas geográficas o territoriales. Sin embargo, mucha agua ha pasado bajo el puente y el Derecho Internacional Privado no solo sigue vigente sino que, en los nuevos escenarios, cobra renovados matices de singular trascendencia.

En efecto, los operadores del ciberespacio, recurriendo al Derecho Internacional Privado, podrán conocer cuál es la ley aplicable a la organización de la actividad que desarrollan, a las relaciones jurídicas que celebran, e incluso podrán ponderar la licitud de sus conductas en la red y, asimismo, conocerán quién será el juez competente en caso de conflicto.

A poco que observemos más detenidamente el fenómeno de Internet y la razón de ser del Derecho Internacional Privado, veremos que más que una amenaza constituye un desafío, un estímulo para encontrar las soluciones más adecuadas a las relaciones jurídicas internacionales, en donde se hallan en juego intereses privados y se ponen en contacto diversos ordenamientos jurídicos, en este peculiar espacio virtual. 
Tal como manifiesta Dreyzin de Klor (2005), "dado el carácter internacional inherente al comercio electrónico, la disciplina jurídica llamada a intervenir es el Derecho internacional privado en tanto le compete regular las situaciones jurídicas de naturaleza privada con elementos extranjeros" (p. 287).

En igual sentido, Huet (2001), profesor de la Universidad de París II (Panthéon - Assas) afirma: "Il convient, pour trancher les litiges que peuvent surgir, de mettre en œuvre les règles classiques du droit international privé. Elles fournissent un cadre de référence éprouvé et, pour une large part, des solutions satisfaisantes" (p. 2).

En similar inteligencia, Internet refuerza su necesidad, su razón de ser:

(...) le développement parfois qualifié de 'sauvage' de $\mathrm{l}^{\prime}$ internet restaure le droit international privé dans sa fonction première: assurer la protection des individus dans toutes les relations affectées c'un élément d' extranéité (...). En outre, c'est bien connu: les conflits de lois naissent du trop pleine, non du vide juridique (...). Tant qu'il existera des divergences entre les systèmes juridiques étatiques, on ne pourra faire l'économie ni des règles de conflits de juridictions ni des règles de conflits de lois. Pour s'en débarrasser, ce n'est donc pas simplement d'un lex electronica et de cybermagistrats dont on aurait besoin; il faudrit uniformiser tout le droit et doter les juges d'une compétence universelle ce qui est inenvisageable étant donné les diverses traditions juridiques (Fauvarque - Cosson, 2001, p. 3).

Asimismo, el Profesor Draetta, que ha estudiado profundamente esta cuestión, refuerza el rol de Derecho Internacional Privado en estos escenarios con estas palabras:

(...) il y a lieu d' écarter l'opinion de ceux qui, en se basant sur le caractère incorporel et, surtout, délocalisé d'Internet, qui est divisé en réseaux et par sites plutôt que par États, considèrent qu'on ne peut lui appliquer les règles traditionnelles de droit international privé. L'opinion de ces derniers est fondée sur l'observation que, puisque des règles traditionnelles de droit international privé visent essentiellement à instaurer un rapport juridique dans un ordre bien défini, elles ne pourraient fonctionner valablement que dans un monde juridique réparti dans des ordres étatiques à caractère territorial (...) il n'y a pas de raison apparente pour ne pas appliquer à Internet et au commerce électronique les règles de droit international privé (conflits de lois et conflits de jurisdictions), internes et conventionnelles, chaque fois que cette application ne présente pas de problèmes particuliers en raison de la nature technique du moyen utilisé (Draetta, 2005, p. 197). 
Por lo tanto, el Derecho Internacional Privado se erige en una herramienta insustituible para regular el espacio virtual.

Sin embargo, este nuevo ámbito en el que se desarrollan un sinnúmero de relaciones jurídicas internacionales de índole privada nos lleva a preguntarnos si nuestra disciplina no requerirá de la adaptación, reformulación de algunas de sus reglas tradicionales y, en todo caso, si ello implicaría una modificación, una transformación de la naturaleza, del objeto, del método o de la finalidad del Derecho Internacional Privado.

Para algunos autores, si bien se requieren, se imponen algunas adaptaciones a los nuevos escenarios; ello de ninguna manera implica un cambio de paradigma. En este sentido se pronuncia, entre otros, Vivien Matteo (2003) refiriéndose puntualmente al ámbito contractual:

(...) desde el punto de vista jurídico, los contratos en el mundo virtual $\mathrm{y}$ en el mundo real en realidad no presentan problemas distintos. Hay dificultades de prueba, como por ejemplo, identificar al 'iniciador' del mensaje; hay dificultades con los domicilios aparentes de los comerciantes individuales o societarios que actúan en la red; también al establecer el verdadero momento de la formación de un contrato, los límites con las situaciones de la responsabilidad extracontractual y otra serie de características, pero en realidad el comercio electrónico y el comercio tradicional presentan los mismos problemas y se ajustan a los mismos principios (...) hay una adaptación de la ciencia jurídica, pero no hay ninguna revolución del Derecho (p. 176).

En efecto, las cuestiones de Derecho Internacional Privado vinculadas a la utilización de la red están diseminadas en las categorías existentes (delitos, contratos, etc.) que hay que adaptar pero no transformar radicalmente.

Es por ello que, según sostiene Oyarzábal (2006), el derecho aplicable a los actos realizados o contratos concluidos o ejecutados por Internet "debe diferir lo menos posible del derecho aplicable fuera de la Red en el espacio real. Ello contribuirá a dar certeza y predictibilidad a las actividades online". A tal fin, el autor propone que más que la construcción de un sistema nuevo, la creación de nuevas reglas para el mundo virtual, lo que es necesario es interpretar y aplicar las reglas clásicas del derecho internacional privado tradicional previstas para el mundo real a las futuras ciberdisputas, teniendo siempre en cuenta su peculiar naturaleza (p. 130).

Sin dudas, los términos y especialmente los puntos de conexión utilizados en las normas indirectas, tan típicas de nuestra disciplina, fueron pensados para funcionar en un espacio físico, territorial, estatal: lugar de celebración, lugar de 
ejecución, lugar de domicilio, establecimiento o residencia habitual, lugar de comisión del acto ilícito, por enumerar tan solo aquellos criterios tradicionalmente utilizados para determinar el juez competente y la ley aplicable.

Tal como afirma Draetta (2005),

(...) dans tous ces cas, la nature incorporelle et délocalisée d 'Internet a posé dès le début, et pose encore, à l' interprète de ces qualifications de nouveaux problèmes, indépendamment de la loi sur la base de laquelle la qualification doit être effectuée, qui, généralement, s'avère être la lex fori, c' est-à-dire la loi à laquelle appartient la règle de conflit (p. 205).

Para otros autores, en cambio, estamos ante un cambio de paradigma, presenciamos una revolución del Derecho Internacional Privado. Existen nuevos problemas que solo pueden explicarse y encontrar soluciones en un nuevo paradigma.

Podríamos decir que "se encuentra en desarrollo un nuevo derecho internacional privado que supera el conflictualismo clásico, a través de un amplio reconocimiento de la autonomía de la voluntad y de la utilización de técnicas de derecho uniforme (...)" (Moreno Rodríguez, 2013, p. 230).

Al respecto, González Campos (2000) nos recuerda que:

(...) la thèse de la disparition de l'ancien paradigme de la règle de conflit a déjà été soutenue en 1976 par H. U. Jessurun d'Oliveira. Néanmoins, même si l'on admet l'existence d'une 'crise' du droit international privé en tant que droit fondé sur une 'localisation' des rapports privés à caractère international rigide et purement formel, une telle conclusion ne semble pas pouvoir être admise aujourd'hui. En effet, ce qui caractérise l'état actuel de notre discipline, d'après $P$. Lagarde, c'est le 'pluralisme des fondements' de ses règles, le législateur de chaque système étatique pouvant choisir entre ceux-ci pour réglementer une matière donnée. D'où une relativité de ces fondements, car aucun principe ne cherche à remplacer les autres príncipes concurrents. Et, de ce fait, on peut estimer que nous sommes dans une période de transition entre l'ancien paradigme de la règle de conflit et le nouveau paradigme non encore consacré, à moins qu'il ne faille s'accommoder de cette réalité complexe, comme le soutiennent les doctrines 'postmodernes' du droit international privé (p. 33).

Este cambio de paradigma ha llevado a Pamboukis (2008) a redenominar la disciplina como "Derecho Transnacional Privado", que sucedería al Derecho Internacional Privado que conocemos: 
le droit transnational privé, succédant au droit international privé, est devenu par l'élargissement de son objet et de sa fonction plus cosmopolite et plus complet, pouvant faire face non plus seulement aux besoins nés de la diversité des ordres juridiques étatiques, mais aussi des ordres non étatiques. Non plus seulement s'agissant de la diversité, mais aussi de l'unité, et ce non pas seulement dans les espaces verticaux, mais aussi horizontaux. Et de ce point de vue le droit transnational privé devra organiser les rapports entre le local, le supranational, l'anational et le global (p. 432).

Según el destacado jurista, este nuevo derecho transnacional privado es "pluriel, social et politique." Es portador de los valores contemporáneos: expresa la libertad a través del principio de autonomía, la igualdad gracias a las normas de policía, la justicia mediante el principio de proximidad y la jurisdiccionalización, el humanismo, a través de la excepción de orden público que protege los derechos fundamentales. Su objeto es "d'ordonner la gouvernance des rapports privés transnationaux. Il a pour objet cette nouvelle taxinomie globale, de saisir et organiser l'olon, être la branche immédiate et médiate de réglementation substantielle des droits individuels" (Pamboukis, 2008, p. 432).

Realizaremos, seguidamente, una breve aproximación a las incidencias de Internet, en los dos problemas tradicionales del DIPr. Veamos.

\section{Los problemas clásicos del DIPr: la jurisdicción competente y el derecho aplicable}

A la hora de procurar respuestas a los problemas de determinación de la jurisdicción y del derecho aplicable en el ciberespacio, una diferenciación que no podemos omitir es entre relaciones contractuales y extracontractuales. Si bien en ambos casos se van a presentar dificultades y desafíos de interés a la hora de regular su nacimiento, desarrollo y extinción en el espacio virtual, en el caso de los conflictos derivados de relaciones contractuales, al menos las que se celebran entre partes iguales podrán ser resueltos en virtud de la autonomía de la voluntad, mientras que en las relaciones extracontractuales, el rol de aquella es muy acotado $\mathrm{y}$, para muchos, inexistente.

\section{IV.1. En materia contractual}

La primera cuestión sobre la que debemos realizar algunas apreciaciones es acerca del carácter doméstico o internacional del contrato electrónico. Solo en el segundo caso, es decir, cuando aquel presente elementos extranjeros objetivamente relevantes, tendrán operatividad las normas y los principios del Derecho 
Internacional Privado y, por ende, podrá desplegar todos sus efectos la autonomía de la voluntad para preseleccionar principalmente la ley aplicable al fondo del contrato, a través de la cual, se resolverán las eventuales controversias que pudieren surgir.

Seguidamente, tendremos que determinar si es un contrato entre empresarios, profesionales o interviene un usuario o consumidor, siendo, por tanto, un contrato de consumo. Sabia distinción que tiene en cuenta la presencia de una parte más débil en su poder de negociación y que se traslada al comercio electrónico, cuando diferenciamos entre el B2B (business to business) y el B2C (business to consumer).

Tampoco es posible soslayar la diferenciación propia del comercio electrónico, entre contratación directa e indirecta, que tiene consecuencias significativas, dado que principalmente es en el primero en el que tanto la celebración como el cumplimiento de las prestaciones se lleva a cabo online, donde se advierten dificultades adicionales para determinar el asiento de la relación contractual.

Por su parte, la autonomía de la voluntad, tanto en el ámbito jurisdiccional, sobre el que volveremos, como respecto de la elección de la ley aplicable tiene un amplio campo de aplicación en los contratos electrónicos. De hecho, cuando de contratos entre empresarios o profesionales se trata, resulta sumamente aconsejable su ejercicio, en tanto, ante la inexistencia actual de reglas específicas, genera un alto margen de certidumbre y seguridad jurídicas.

Sin perjuicio de ello, así como la autonomía de la voluntad es un principio de reconocida trayectoria y desempeño en el ámbito de los negocios internacionales, que admite límites, en el contexto del comercio electrónico también debe reconocer restricciones. Entre las principales, el consabido orden público internacional, el fraude a la ley, las normas de policía del foro y eventualmente de un tercer Estado, la protección del usuario y consumidor, ante la posible imposición por parte del contratante profesional de la ley aplicable, muy frecuente en los denominados click and wrap agreement, la versión cibernética de los contratos de adhesión.

Ahora bien, la mayor dificultad la encontramos precisamente cuando los contratantes no han hecho uso de la autonomía de la voluntad, o bien habiendo elegido ley aplicable el acuerdo resulta inválido o ineficaz. Entonces, ¿los puntos de conexión clásicos en materia de contratos internacionales son apropiados cuando de contratación celebrada por medios electrónicos se trata?

Evidentemente, respecto del lugar de cumplimiento, punto de conexión previsto por el Código Civil y Comercial de la Nación (CCiv. y Com.), en defecto de elección de derecho aplicable, así como en los Tratados de Montevideo de Derecho Civil Internacional de 1889 y de 1940, mientras que en el comercio electrónico 
indirecto no crea dificultades adicionales y peculiares; en el comercio electrónico directo, los problemas para su localización pueden ser superados si los contratantes pactaron un lugar de cumplimiento, aun cuando resulte ficticio, pues en definitiva la transacción se ejecuta en línea. De no ser así, se podría recurrir, al menos en materia de comercio B2B a la teoría de la prestación más característica, tal como también está dispuesto en nuestra fuente interna para calificar "lugar de cumplimiento" (artículo 2652) entendiendo que el prestador más característico es el denominado proveedor de servicios de la información.

Por su parte, en el caso del lugar de celebración, tal como en subsidio y a falta de determinación del lugar de cumplimiento recurren tanto el Código Civil y Comercial como el Tratado de Montevideo de 1940, su localización dependerá de la teoría adoptada respecto del perfeccionamiento de los contratos. En general, en los contratos entre empresas, se considera que el lugar de celebración coincide con el domicilio o establecimiento del proponente, del iniciador, en consonancia con la teoría de la recepción, de amplia acogida en el derecho comparado. En cambio, en los contratos de consumo, se entiende que se encuentra en el lugar de la residencia habitual del consumidor.

Cabe señalar que, en consonancia con lo dispuesto por la Convención de Naciones Unidas sobre la Utilización de las Comunicaciones Electrónicas en los Contratos Internacionales de 2005, en todo caso debe distinguirse el establecimiento real de los domicilios virtuales, en páginas web o correos electrónicos, que no generan presunción fiable alguna, dado el carácter efímero y desconectado con la realidad que poseen. Estas peculiares características permitirían a cualquiera de las partes colocarse fácilmente en una posición más favorable a sus intereses, eludiendo normas imperativas. En consecuencia, optar por el domicilio virtual propiciaría la ocasión de cometer fraude a la ley. Tampoco puede considerarse establecimiento el lugar donde se encuentra el servidor o el equipo o la tecnología utilizados por cada una de las partes.

En suma, a nuestro criterio, la mejor opción está a favor de los criterios tradicionales que conectan al contrato con el mundo real, con sus circunstancias fácticas y objetivas.

Sin embargo, la complejidad que presentan algunos contratos electrónicos puede habilitar el recurso excepcional a la cláusula de escape que permite al juez inclinarse a favor de un derecho distinto al que indiquen las conexiones clásicas, siempre que funde razonablemente la existencia de un derecho más próximo, que posea vínculos más estrechos con el contrato (artículo 2653 CCiv. y Com.).

Por otra parte, en los contratos electrónicos de consumo la protección de la parte más débil, del denominado "consumidor pasivo", amerita la limitación de la 
autonomía de la voluntad y su protección por las leyes del lugar de su residencia habitual, si resultaran más favorables.

En efecto, los ordenamientos jurídicos nacionales contienen tales normas para la protección de estos sujetos considerados jurídicamente débiles, cuyo conocimiento es de particular importancia si consideramos que la web es un incomparable medio de difusión, publicidad, exhibición, oferta y venta de bienes y servicios a los consumidores de la aldea global. En consecuencia, las normas del foro protectorias del consumidor podrían desplazar la legislación extranjera elegida en un contrato B2C. Ya la Convención de Roma sobre la Ley Aplicable a las Obligaciones Contractuales de 1980, en su artículo 5, preveía este límite a la autonomía de las partes (1). En similares términos se expresa el actual Reglamento (CE) No 593 del 17 de junio de 2008 sobre la misma materia en su artículo 6.2.

La importancia de esta limitación radica principalmente en el considerable número de contratos de consumo, generalmente por adhesión, que actualmente se celebran online(2).

Recordemos que en lo que concierne al Código Civil y Comercial de la Nación Argentina está prohibido el ejercicio de la autonomía de la voluntad en los contratos de consumo (artículo 2651, última parte).

En tanto que el Acuerdo sobre Derecho Aplicable en Materia de Contratos Internacionales de Consumo (Mercosur/CMC/DEC. № 36/17), aún no vigente, diferencia la determinación del derecho aplicable según los contratos sean celebrados en el estado del domicilio del consumidor y cuando se celebran fuera de este. En el primer caso, los contratos, especialmente en caso de contratación a distancia, se rigen por el derecho elegido por las partes, quienes pueden optar por el derecho del domicilio del consumidor, del lugar de celebración o cumplimiento del contrato o de la sede del proveedor de los productos o servicios. El derecho elegido será aplicable siempre que fuera más favorable al consumidor. En el segundo caso, se rigen por el derecho elegido por las partes, quienes pueden optar válidamente por el derecho del lugar de celebración o de cumplimiento del contrato o por el del domicilio del consumidor. El derecho elegido también será aplicable siempre que fuera más favorable al consumidor.

(1) El artículo 5 del Convenio de Roma sobre la ley aplicable a las obligaciones contractuales establecía que: "Sin perjuicio de lo dispuesto en el artículo 3 la elección por las partes de la ley aplicable no podrá producir el resultado de privar al consumidor de la protección que le aseguren las disposiciones imperativas de la ley del país en que tenga su residencia habitual".

(2) Sin embargo, algunos autores han advertido que no debería hacerse una aplicación indiscriminada de la ley del domicilio o residencia habitual del consumidor fundada simplemente en las particularidades de las nuevas tecnologías y formas de comunicación (Oyarzábal, 2003, p. 3). 
Podemos apreciar que el acuerdo sigue la tendencia predominante en la materia, que consiste en admitir la autonomía de la voluntad, pero limitada y en tanto la elección del derecho aplicable resulte en beneficio del consumidor (orientación material). Es decir, la elección debe recaer en algunas de las leyes alternativas que menciona la norma de forma taxativa a modo de catálogo.

Por su parte, para el caso en el que las partes no hayan ejercido la autonomía de la voluntad, se aplicará: 1) el derecho del domicilio del consumidor en el caso de la contratación internacional a distancia cuando el consumidor está en el país de su domicilio, y 2) el lugar de celebración para el caso de contratación internacional cuando el consumidor está fuera de su estado de domicilio.

El acuerdo del Mercosur especialmente se ocupa del caso de la contratación en línea, en la cual la elección del derecho aplicable debe estar expresada en forma clara y destacada en todas las informaciones brindadas al consumidor (Scotti, 2019).

En materia jurisdiccional, consideramos que en los contratos $\mathrm{B} 2 \mathrm{~B}$, el acuerdo de elección de foro debe tener un reconocimiento amplio. A tales fines, resulta imperiosa la recepción del principio de equivalencia funcional en relación con el propio acuerdo o pacto de selección de juez de tal modo que se le reconozca la misma validez formal ya sea que se celebre por medios electrónicos o por escrito, en el sentido clásico del término. Así lo ha entendido el legislador argentino en el artículo 2607 CCiv. y Com.

En cuanto a las relaciones B2C, debe estudiarse cautelosamente el acuerdo de prórroga. Habría que analizar caso por caso a fin de dilucidar si fue impuesta al consumidor de modo abusivo y sobre todo si su puesta en práctica implica una limitación al acceso a la justicia. En el caso del derecho argentino, de fuente interna, la elección de foro está vedada en los contratos de consumo (artículo 2654 CCiv. y Com.).

Respecto de los criterios subsidiarios atributivos de jurisdicción, entendemos que debe reconocerse, con cierta flexibilidad, un abanico de foros disponibles, siempre que posean alguna vinculación razonable con la controversia, que permitan el ejercicio acabado del derecho de defensa en juicio y el efectivo reconocimiento y ejecución extraterritorial de la sentencia que recaiga en el asunto, tal como en líneas generales, lo hace el artículo 2654 CCiv. y Com.

Por su parte, en las relaciones empresariales, el arbitraje comercial internacional tiene reconocidas y probadas ventajas que son trasladables al contexto electrónico. Ello fue tenido en cuenta para la modificación de las exigencias de forma del acuerdo arbitral por UNCITRAL/CNUDMI en la versión 2006 de la Ley Modelo sobre Arbitraje Comercial Internacional, la que fuera adoptada por nuestro país a través de la sanción de la Ley 27.449. 


\section{2. En materia extracontractual}

Respecto de la responsabilidad civil extracontractual, debe tenerse en cuenta que los daños que se producen mediante Internet (a la intimidad, a la imagen, a la dignidad, al honor, a la libertad sexual, a la propiedad intelectual e industrial, a los consumidores, a los menores, a través de la pornografía, del tráfico de armas, etc.) pueden alcanzar a todo el globo, pueden diseminarse en cada país del mundo. Los ilícitos por Internet son "ilícitos a distancia" e ilícitos producidos en varios países.

Surge, entonces, un interrogante inmediato: ¿cómo podrán sancionarse la inmensa variedad de actos ilícitos en la red e indemnizar a las víctimas cuando el daño puede ser sufrido en todos los países del mundo a la vez? Sin dudas, estamos ante una situación inédita.

En relación con la ley aplicable, el criterio clásico es el lugar de comisión del delito (lex loci delicti). Es una antigua discusión entre los iusprivatistas, si la lex loci delicti es la ley del lugar de generación o de producción del daño (por esta última se ha inclinado nuestro legislador en el artículo 2657 CCiv. y Com.).

En Internet el debate se centra en la ley del país de emisión $v s$. la/s ley/es del/de los país/es de recepción. Optar por la ley del país de emisión tiene por principales ventajas brindar previsibilidad para el autor del daño, y la mayor factibilidad en el reconocimiento y ejecución de sentencia en dicho país (deber ser considerado un ilícito en el país de emisión para obtener la ejecución de la sentencia). Elegir el criterio de la ley del país de recepción impide el riesgo de transferencia de los servidores a potenciales paraísos - internet (con leyes muy liberales). Además, milita a su favor el principio de reparación integral del daño. Sin embargo, la desventaja es la potencial aplicación de todas las leyes del planeta, aún contradictorias entre sí, generando una decisión inejecutable. Ello afecta la seguridad jurídica y la tutela judicial efectiva. Es evidente que el eventual responsable no puede comprometerse a cumplir numerosas leyes a la vez. Así, corremos el riesgo de paralizar el desarrollo del comercio electrónico pues resulta imposible conformar a todas las leyes de los países de recepción, ya que cada Estado donde hay una computadora y una conexión telefónica constituiría lugar del delito.

En materia de jurisdicción, en el ámbito de Internet(3), la posibilidad de forum shopping es mucho mayor debido a la multiplicidad de foros disponibles. En

(3) En dos casos resueltos por el Tribunal de Justicia de la Unión Europea (TJUE), el Abogado General Cruz Villalón en dos asuntos acumulados, eDate Advertising (C 509/09) y Martínez y Martínez (C 161/10), rechaza la mera accesibilidad de la información en un país como fundamento para la atribución de competencia a sus tribunales ( $v g r$ casos "Yahoo" y "Gutnick") y propone que el artículo 5.3 del Reglamento Bruselas I atribuye también competencia a los órganos jurisdiccionales del Estado miembro donde se localice el "centro de gravedad del conflicto". Dicho lugar sería el Estado miembro 
efecto, el daño puede ser considerado virtualmente sufrido en todos los países en los que la información dañina pueda ser accesible. En este sentido, cabe preguntarse: ¿qué entendemos por el lugar donde el daño se generó y dónde se produjo? Nos hallamos en presencia de un problema de calificaciones. En cualquier caso, el lugar del domicilio del demandado siempre será considerado un foro razonable.

\section{Mecanismos alternativos para la solución de controversias en Internet}

Los “ODR" (Online Dispute Resolution) son aquellos métodos de resolución de conflictos que se llevan a cabo mediante el uso de la tecnología de la información y de la comunicación, especialmente Internet. En principio, se desarrollan de forma completamente virtual, pero pueden configurarse también de manera híbrida mediante la celebración de una o varias sesiones presenciales, llevándose a cabo las etapas básicas del procedimiento (presentación de escritos, notificaciones, deliberaciones y resultados) mediante el uso de la tecnología, principalmente, el email, el chat, mensajes instantáneos, la teleconferencia o la videoconferencia.

Estos métodos han surgido y se han implementado en aquellos conflictos derivados de las transacciones celebradas vía Internet. Sin embargo, nada obsta para que se amplíe su ámbito de actuación.

Entre las ventajas que brindan los mecanismos alternativos de resolución de controversias online podemos mencionar: son flexibles, rápidos y efectivos; eliminan los gastos e incomodidades de los traslados, ya que se puede participar activamente a distancia, cruzando las fronteras estatales, sin trasladarse físicamente; son seguros y confidenciales ya que la tecnología brinda diversos mecanismos de seguridad, como la encriptación de datos, la firma digital, entre otros; evitan los inconvenientes del "face to face", la mala interpretación de expresiones faciales o gestos corporales, el lenguaje amenazador, los actos violentos, que ocasionan animosidad en los contrincantes y pueden llevar a una escalada del conflicto. La distancia entre ellos muchas veces puede ser necesaria para el éxito en la búsqueda de la mejor solución. Además, pueden proveer la especialización y la expertise que requieren muchas disputas para ser analizadas, comprendidas, y solucionadas.

No obstante, también se advierten algunas desventajas: la inexistencia de reglas y principios claros en la materia; la existencia de barreras lingüísticas; la falta de transparencia y de credibilidad de los sitios web que brindan estos servicios; la falta de seguridades en el intercambio de documentación confidencial; la falta de comunicación verbal, del lenguaje del cuerpo, de los sonidos, que en muchas ocasiones contribuyen a alcanzar una solución del diferendo; la poca familiaridad

de la UE en cuyo territorio la información litigiosa resulta objetiva y particularmente relevante y donde, al mismo tiempo, el titular del derecho de la personalidad tiene su "centro de intereses". 
de muchos personas con estos métodos e incluso la falta de acceso de porciones importantes de la humanidad.

Sin embargo, el mayor escollo que encontramos a los ODR en cualquier ámbito son las escasas posibilidades de ejecución judicial que pueden tener estos acuerdos ante la carencia de marcos legales adaptados a la solución online de disputas.

Cabe señalar, como un avance en materia de ODR, que en su $43^{\circ}$ período de sesiones, la Comisión de las Naciones Unidas para el Derecho Mercantil Internacional (CNUDMI), "observando el rápido aumento de las operaciones transfronterizas que se realizan en línea y, paralelamente, la necesidad de contar con mecanismos encaminados a resolver las controversias que traen aparejadas esas operaciones", decidió emprender un estudio en la esfera de la solución de controversias en línea. En tal inteligencia aprobó las Notas técnicas sobre la solución de controversias en línea (4) en su $49^{\circ}$ período de sesiones, celebrado en 2016. Constituye un instrumento descriptivo no vinculante en el que se recogen los elementos del sistema de solución de controversias en línea, cuya finalidad es promover el desarrollo de la ODR y prestar asistencia a los administradores ODR, las plataformas ODR, los terceros neutrales y las partes en un proceso ODR.

La introducción advierte que la ODR abarca una amplia gama de enfoques y formas (por ejemplo, el mecanismo del ombudsman, las juntas de reclamaciones, la negociación, la conciliación, la mediación, el arreglo facilitado, el arbitraje y otros), incluidos los procesos híbridos que puedan llegar a existir, con elementos tanto en línea como fuera de línea.

Las Notas técnicas reflejan enfoques, en relación con los sistemas ODR, que respetan los principios de imparcialidad, independencia, eficiencia, eficacia, debido proceso, equidad, rendición de cuentas y transparencia.

El propósito es que las Notas técnicas se utilicen para resolver controversias emanadas de contratos transfronterizos de compraventa o de servicios de poca cuantía celebrados por medios de comunicación electrónicos.

\section{Beneficios y desafíos de las TIC en el sector de la cooperación jurídica internacional}

Ahora bien, en el sector de la cooperación jurídica internacional, Internet y las nuevas tecnologías nos abren un horizonte muy amplio para indagar múltiples formas de facilitarla.

(4) Recuperado de https://uncitral.un.org/sites/uncitral.un.org/files/media-documents/uncitral/es/v1700385_spanish_technical_notes_on_odr.pdf [Fecha de consulta: 22/01/2020]. 
En general, el incremento de las relaciones privadas internacionales ha determinado, consecuentemente, un considerable aumento de los litigios suscitados en torno a ellas. Ante esta realidad, asistimos a un significativo auge normativo de la cooperación procesal internacional y sus cuestiones conexas (Tellechea Bergman, 2009).

\section{Como bien destaca Fernández Arroyo (2008),}

(...) al día de hoy resulta una verdad de perogrullo que las cuestiones 'procesales' y 'cooperacionales' del DIPr. han desplazado en su interés y desarrollo a las que conciernen al derecho aplicable al fondo, las cuales tradicionalmente habían sido consideradas como el contenido esencial -y, en algunos casos, único- de la disciplina (p. 295).

En primer lugar, recordemos que el instituto de la cooperación consiste en la entreayuda que se prestan los órganos jurisdiccionales de los Estados con el propósito de no interrumpir la continuidad de un proceso incoado ante un tribunal, que se ve necesitado de solicitar asistencia a otro tribunal foráneo (Dreyzin, 2010, p. 264).

Incluye

(...) toda actuación procesal desplegada en un Estado al servicio de un proceso incoado o a incoarse en otro. Actividad originada en providencias emanadas de órganos jurisdiccionales extranjeros, cuya finalidad es lograr que el proceso se entable, se desarrolle o se afiance en sus resultados, a través de acciones que los órganos jurisdiccionales locales han de llevar a cabo (Tellechea Bergman, 2002, p. 219).

Sin dudas, las nuevas tecnologías pueden facilitar y agilizar la cooperación interjurisdiccional, máxime si la comprendemos como una obligación internacional de todo Estado (artículo 2611 CCiv. y Com.).

El establecimiento e implementación de la figura de las autoridades centrales, a partir del Convenio de La Haya de 15 de noviembre de 1965 sobre notificación o traslado en el extranjero de documentos judiciales y extrajudiciales en materia civil o comercial(5), constituyó un significativo avance en la agilización y eficiencia de la cooperación jurídica internacional, sobre todo en comparación con las modalidades tradicionales que implicaban que toda solicitud o petición de cooperación en otro Estado pasaba del órgano jurisdiccional que lo solicitaba, a través

(5) Es de destacar que una figura similar a la autoridad central la encontramos ya en el Convenio de Nueva York de 20 de junio de 1956 sobre obtención de alimentos en el extranjero. 
del Ministerio de Justicia y del de Relaciones Exteriores, a los respectivos del otro Estado, que debían hacerla llegar al órgano jurisdiccional destinatario que practicaba el pedido solicitado, volviendo la comisión, una vez cumplimentada y por las mismas vías, al órgano jurisdiccional requirente.

Este mecanismo ha sido calificado como:

Un largo camino, de dudosa efectividad, y generador de plazos tan amplios como inasumibles, si lo que se pretende es conseguir hacer efectiva la tutela judicial en el ámbito internacional. La globalización, la supresión de 'fronteras' en algunos espacios jurídicos internacionales, y una mayor transparencia y confianza mutua en el ámbito de la cooperación internacional, han ido puliendo formas de cooperación y comunicación tradicionales y generando nuevos mecanismos o herramientas acordes a las nuevas tecnologías que, en el siglo XXI, forman parte ya del trabajo cotidiano de los operadores jurídicos (Forcada Miranda, 2017, p. 47).

Sin embargo, la mayoría de las normas vigentes contienen exigencias que no se compadecen con las tecnologías de comunicación que hoy tenemos a disposición.

En pos de una interpretación más favorable a la implementación de las TIC, el artículo 4.5 de los Principios ASADIP sobre el Acceso Transnacional a la Justicia (Principios TRANSJUS), aprobados por la Asamblea de la Asociación Americana de Derecho Internacional Privado, en su reunión celebrada en Buenos Aires, el 12 de noviembre de 2016 (6) señala que:

(...) el Estado requerido aplicará e interpretará las normas de cooperación interjurisdiccional de manera especialmente flexible, minimizando la relevancia de los formalismos. Los tribunales del Estado requerido podrán actuar de oficio y emprender las adaptaciones normativas que sean necesarias para lograr la realización de la actuación procesal correspondiente. Cuando la ley no señale una forma, método o modo determinado para llevar a cabo algún acto de cooperación solicitado por el Estado requirente, los tribunales del Estado requerido tienen la facultad de tomar todas aquellas medidas idóneas para lograr el objetivo de la asistencia requerida, resguardando siempre las garantías procesales fundamentales.

Se desprende de este Principio la necesidad de buscar el delicado equilibrio entre el deber de cooperación, a través de medios disponibles e idóneos y el respeto de las garantías del debido proceso.

(6) Recuperado de http://www.asadip.org/v2/wp-content/uploads/2018/08/ASADIP-TRANSJUS-ES-FINAL18.pdf [Fecha de consulta: 22/01/2020]. 
Sin dudas, "la utilización de las TIC (técnicas de la información y la comunicación) puede representar una gran ayuda para el diligenciamiento de soluciones 'on line'" (Cerdeira, 2017, p. 126), y en consecuencia se erigen medios de fácil disposición e implementación para la cooperación entre autoridades de distintos Estados, pero que corresponderá regular a fin de garantizar los derechos de las partes.

Tal como señala Véscovi (2019),

(...) en los últimos años hemos asistido, con el desarrollo de los medios de comunicación y la tecnología, a la posibilidad de comunicaciones directas entre los jueces de diferentes países (o autoridades centrales), audiencias por video conferencia, se comienza a vislumbrar la posibilidad del exhorto electrónico (lo que eliminaría las otras vías de transmisión, tanto más lentas). Además de todo ello se han instrumentado guías de buenas prácticas para que los temas burocráticos no enlentezcan, dificulten o impidan la cooperación, redes de contacto, jueces de enlace, etc. (...). Todo lo anterior ha contribuido, sin duda, al mejoramiento del acceso a la justicia, por parte de los ciudadanos. Pero (...) aún falta bastante por hacer (p. 6).

Mencionaremos, a continuación, algunos de los avances realizados hasta el momento.

\section{VI.1. Comunicaciones judiciales directas $(7)$}

Los medios de comunicación, generados a través de las nuevas tecnologías, bajo los que las comunicaciones judiciales directas pueden establecerse es un tema de interés actual de los foros internacionales. La necesidad de métodos seguros de comunicación, el uso de plataformas creadas ad hoc para los miembros de la Red Internacional de Jueces de La Haya, y el acceso a las nuevas tecnologías, como la videoconferencia, con la finalidad de hacer confiables y seguras las comunicaciones judiciales directas, son temas de "preocupación, tanto para la Conferencia de La Haya como para muchos miembros de la IHNJ, a quienes sus gobiernos no proveen de correos electrónicos oficiales, viéndose obligados a recurrir a plataformas de escasa o nula seguridad por referencia a Yahoo, Hotmail y Gmail" (Forcada Miranda, 2017, p. 390).

(7) Las comunicaciones judiciales directas internacionales (CJD) "son comunicaciones entre dos autoridades judiciales de distintos países que se desarrollan sin la intervención de una autoridad administrativa (autoridades intermediarias), como es el caso habitual de los exhortos internacionales que tramitan usualmente a través de Cancillerías y/o Autoridades Centrales designadas por el propio país (generalmente administrativas)" (Goicoechea, 2016, p. 136). 
En efecto, los miembros de la Red de La Haya enfatizaron la importancia de que la Conferencia de La Haya implemente, tan pronto como sea posible, medios de comunicación segura basados en internet, como correo electrónico seguro y sistemas de videoconferencia, con miras a facilitar el trabajo en red y reducir los costos derivados de las comunicaciones telefónicas (Reunión Interamericana de Jueces y Autoridades Centrales de la Red Internacional de La Haya sobre Sustracción Internacional de Menores, 2011).

De hecho, existe una íntima relación entre los medios tecnológicos que pueden emplearse para facilitar y mejorar las comunicaciones judiciales directas, por un lado, y las garantías y salvaguardias que deben preservarse, por el otro.

Además, es una realidad innegable que no todos los Estados han alcanzado el mismo o similar nivel tecnológico ni todos los operadores jurídicos, principalmente los jueces en este caso, están igualmente capacitados.

Sin perjuicio de las comunicaciones por correo electrónico y por videoconferencia, de la que nos ocuparemos seguidamente, una cuestión que ha despertado un particular interés es la creación e implementación de plataformas seguras de comunicación, diseñadas especialmente para la cooperación internacional con la finalidad de dotarla de mayor seguridad, como son los sistemas denominados Iber@ en IberRed y Groove en el ámbito de la OEA, el Compendium en la Red Judicial Europea Civil y Mercantil y el sistema de comunicación de Eurojust.

A su turno, la Conclusión No 66 sobre uso de la informática para apoyar el establecimiento de contactos y las comunicaciones de la Séptima reunión de la Comisión Especial sobre el funcionamiento práctico del Convenio de 1980 sobre Sustracción Internacional de Menores y del Convenio de 1996 sobre Protección de Niños (10-17 de octubre de 2017) indica que reconoce el valor del uso de la tecnología de la información para una comunicación eficiente y para compartir información, e invita a la Oficina Permanente a continuar explorando, si la existencia de recursos lo permite, el desarrollo de un sistema seguro de comunicación, como un servicio de videoconferencias seguro, en particular para los miembros de la RIJLH.

Asimismo, el Proyecto de documento para informar a abogados y jueces sobre comunicaciones judiciales directas en casos específicos en el marco de la Red Internacional de Jueces de la Haya expresa que los jueces deben usar las opciones tecnológicas más apropiadas para facilitar una comunicación lo más eficiente y rápida posible (Conferencia de La Haya, 2017). 
INCIDENCIAS DE LAS NUEVAS TECNOLOGÍAS EN EL DERECHO INTERNACIONAL PRIVAdo

- LUCIANA B. SCOTTI (PP. 409-442)

\section{VI.2. La videoconferencia}

Dentro de las TIC cumple un rol destacado la videoconferencia, que ha sido definida como:

un sistema interactivo de comunicación que transmite simultáneamente y 'en tiempo real' la imagen, el sonido y los datos a distancia (en conexión punto a punto), permitiendo relacionar e interactuar, visual, auditiva y verbalmente, a un grupo de personas situadas en dos o más lugares distintos como si la reunión y el diálogo se sostuviese en el mismo lugar. En definitiva, mediante la videoconferencia se conectan entre sí varios puntos distantes. En cada punto se sitúa un equipo que transmite la imagen y el sonido del acto que se está practicando y que, al mismo tiempo, recibe en un monitor de alta resolución la imagen y el sonido de lo que está ocurriendo en el otro punto. Con ello se permite una comunicación bidireccional plena en tiempo real en el que el efecto es un 'acto' o 'reunión' al que asisten personas que se encuentran en lugares diferentes (Tirado Estrada, 2017, p. 154).

Como destaca Goicoechea (2016), "la videoconferencia es una herramienta que se viene incorporando paulatinamente a la práctica de la cooperación judicial internacional" (p. 142), siendo utilizada con más frecuencia en materia penal, tanto a nivel interno como a nivel internacional, pero también en materia de restitución internacional de niños y en otros ámbitos civiles y mercantiles.

En el ámbito de la cooperación penal, varios instrumentos admiten el recurso tecnológico de la videoconferencia, tales como el Estatuto de la Corte Penal Internacional, aprobado en el marco de la Conferencia de Roma el 17 de julio de 1998; el Convenio Europeo relativo a la Asistencia Judicial en Materia Penal, aprobado el 29 de mayo de 2000 por el Consejo de Ministros de Justicia y Asuntos Exteriores de la Unión Europea; el Segundo Protocolo Adicional de 2001 (Estrasburgo, 8 de noviembre de 2001) a la Convención Europea de Asistencia Mutua en Materia Penal, suscrita en Estrasburgo el 20 de abril de 1959 por los miembros del Consejo de Europa; la célebre Convención de Palermo de 2000 sobre Delincuencia Organizada Transnacional, la Convención de Naciones Unidas contra la Corrupción, de Mérida, 2003, entre los principales.

En el ámbito de la cooperación civil, la Conclusión No 4 de la Comisión Especial de 2003 de la Conferencia de La Haya de Derecho Internacional Privado, que evaluó el funcionamiento del Convenio de La Haya de 1970 sobre obtención de pruebas en el extranjero (conjuntamente con los Convenios de la Apostilla de 1961, y Notificaciones de 1965), estableció que si bien la aplicación de las nuevas tecnologías no había sido considerada al momento de la negociación de estos 
instrumentos, el espíritu y letra de dichos Convenios no constituía un obstáculo para su utilización, y sin lugar a dudas el funcionamiento de estos Convenios se vería optimizado sustancialmente mediante la aplicación de las nuevas tecnologías. En igual sentido se pronunció la Conclusión No 55 de la Comisión Especial de 2009.

Asimismo, la Comisión Especial de 2014 sobre la obtención de pruebas mediante enlaces de video recordó que su uso para facilitar la obtención de pruebas en el extranjero es compatible con el marco del Convenio sobre Obtención de Pruebas. Reconoce, asimismo, que el artículo 17 de tal tratado no impide que un miembro del personal judicial del tribunal requirente (u otra persona debidamente designada), situado en un Estado contratante, pueda interrogar a una persona que se encuentra en otro Estado contratante mediante enlace de video.

En la Unión Europea, el Reglamento (CE) No 1206/2001 del Consejo, del 28 de mayo de 2001, relativo a la cooperación entre los órganos jurisdiccionales de los Estados miembros en el ámbito de la obtención de pruebas en materia civil o mercantil, prevé expresamente el uso de la videoconferencia para la obtención de pruebas en el extranjero (artículos 10 apartado 4 y 14 apartado 4).

Asimismo, el Reglamento (UE) 2019/1111 del Consejo, de 25 de junio de 2019, relativo a la competencia, el reconocimiento y la ejecución de resoluciones en materia matrimonial y de responsabilidad parental, y sobre la sustracción internacional de menores, en su considerando 53 expresa que cuando no sea posible oír a una parte o a un menor en persona, y cuando se disponga de los medios técnicos necesarios, el órgano jurisdiccional puede considerar la posibilidad de celebrar una audiencia mediante videoconferencia o por cualquier otro medio de tecnología de la comunicación, a menos que, teniendo en cuenta las circunstancias particulares del caso, el uso de dicha tecnología no fuera adecuado para el correcto desarrollo del proceso.

Es destacable que en diciembre de 2010 la Conferencia de Ministros de Justicia de Iberoamérica (COMJIB), reunida en Mar del Plata, aprobó el "Convenio Iberoamericano sobre el Uso de la Videoconferencia en la Cooperación Internacional entre Sistemas de Justicia", y su Protocolo Adicional, en vigor desde el 17 de julio de 2014.

El mencionado Convenio favorece el uso de la videoconferencia entre las autoridades competentes de los Estados Partes como un medio concreto para fortalecer y agilizar la cooperación mutua en materia civil comercial y penal y en otras materias que las Partes acuerden de manera expresa (artículo 1). 


\section{VI.3. El exhorto electrónico}

Párrafo aparte merece la implementación de la tecnología para la transmisión de los exhortos a autoridades extranjeras.

Al respecto, Véscovi (2019) advierte que: "En el estado actual del desarrollo de la tecnología, casi que no tiene más sentido la existencia del exhorto físico, debemos implementar urgentemente la vía del exhorto electrónico" (p. 14).

Especialmente en el ámbito penal,

(...) las Autoridades Centrales designadas para ciertos convenios están recibiendo, con relativa frecuencia, exhortos electrónicos que se adelantan en medio electrónico (generalmente por correo electrónico, y en algunos casos a través de sistemas de comunicación segura -eg. 'Groove' o 'Iber@'). En estos casos generalmente las Autoridades Centrales están llevando adelante diligencias en base al documento recibido en forma electrónica y para cuando llega el documento en soporte papel, la diligencia ya se ha realizado y por ende el documento papel se archiva. Es decir, en cierta medida el papel se está tornando obsoleto (Goicoechea, 2016, p. 148).

También las solicitudes de restitución internacional de niños suelen ser anticipadas a través de correo electrónico, para poder dar comienzo al trámite en forma inmediata dada la urgencia del tipo de procedimiento.

En tal sentido, la Comisión Especial de 2014 sobre el funcionamiento práctico de los Convenios de La Haya sobre Notificación, Obtención de Pruebas y Acceso a la Justicia señaló que el funcionamiento práctico del Convenio sobre Obtención de Pruebas mejoraría si se lograra la ejecución de las cartas rogatorias con más rapidez, y si se optimizaran las comunicaciones con las autoridades centrales, en especial con el uso del correo electrónico en todas las etapas de la ejecución de las cartas rogatorias.

En este tema reviste particular interés el Tratado de Medellín, relativo a la Transmisión Electrónica de Solicitudes de Cooperación Jurídica Internacional entre Autoridades Centrales, aprobado en la Asamblea Plenaria Extraordinaria de La Antigua, Guatemala, en 2018, cuya firma fue finalmente habilitada en la XXI Asamblea Plenaria de la Conferencia de Ministros de Justicia de los Países Iberoamericanos (COMJIB), celebrada en la ciudad de Medellín, Colombia, los días 24 y 25 de julio de 2019. Este Tratado fue firmado por Argentina, Brasil, Colombia, Chile, España, Paraguay, Portugal y Uruguay (8).

(8) No se encuentra aún en vigor. Para ello, el Tratado exige que se depositen al menos tres instrumentos de ratificación o adhesión y que transcurran 90 días naturales desde el depósito del último 
Este acuerdo internacional no contiene nuevos requisitos formales, procesales o sustanciales de los exhortos, sino que complementa los tratados que se encuentren vigentes en materia de cooperación a fin de facilitar la transmisión de los exhortos a través de la plataforma Iber@ (9). Por ende, el pedido de cooperación será efectuado por las autoridades judiciales en virtud y conforme los tratados internacionales o, en su defecto, de las normas de fuente interna en materia de cooperación. Así lo dispone el artículo 8.

En definitiva, el objetivo principal del tratado es la regulación del uso de la plataforma Iber@ "como medio formal y preferente de transmisión de solicitudes de cooperación jurídica internacional entre Autoridades Centrales, en el marco de los tratados vigentes entre las partes y que contemplen la comunicación directa entre dichas instituciones" (artículo 1). En la práctica, su implementación eliminaría completamente la transmisión en soporte papel.

\section{A modo de colofón}

Internet, la web, el espacio virtual, el mundo cibernético constituyen un escenario novedoso, inusitado, asombroso, que origina múltiples oportunidades a quienes desean operar en él. Sin embargo, a la vez, trae consigo una gran incertidumbre jurídica, que conspira en gran medida con su pleno despliegue y evolución.

Los operadores del Derecho, legisladores, jueces, abogados, asesores legales, docentes e investigadores tienen ante sí un desafío importante: crear, proponer, evaluar y aplicar reglas jurídicas idóneas para este nuevo ámbito, que, en definitiva, fue creado por el propio hombre.

El mundo real y el virtual interactúan en forma permanente. Las relaciones sociales, y también las jurídicas, se llevan a cabo en uno y otro espacio, que en algunos casos compiten y en otros se complementan.

de ellos (artículo 11.5). Además, su vigencia está condicionada a: 1) la previa aprobación del Reglamento de financiación de la plataforma Iber@; 2) la puesta en conocimiento de las Partes de un manual técnico de Iber@, que defina parámetros, especificaciones y requisitos técnicos y de seguridad, encriptación y protección de datos, que la plataforma deberá respetar; 3) el completo funcionamiento de la plataforma Iber@, de conformidad con lo establecido en el Manual técnico.

(9) Iber@ es una página web de la Red Iberoamericana de Cooperación Jurídica Internacional (IberRed) con un acceso público y otro privado que constituye un sistema de comunicación seguro para los puntos de contacto y autoridades centrales. La seguridad del sistema Iber@ y su fácil uso y accesibilidad permiten un "entorno colaborativo 2.0" por el cual los miembros pueden interactuar para optimizar la gestión del conocimiento con respecto a lo desarrollado por IberRed. Además, Iber@ no requiere de un software, permitiendo su uso desde cualquier computadora gracias a su sistema de autenticación, y permitiendo también una comunicación segura y en tiempo real, sin importar dónde se encuentra el punto de contacto. 
Dado que no son compartimentos estancos, tampoco pueden ser tratados como espacios jurídicos desconectados, porque en definitiva somos los mismos seres humanos los que nos movemos, comunicamos, comerciamos, nos relacionamos en uno y en el otro. Los problemas suelen ser los mismos o muy similares $\mathrm{y}$, en consecuencia, las soluciones no pueden ser divergentes.

Cualquier distinción de fondo al regular los conflictos jurídicos que surgen en el mundo real y en el mundo virtual conspiraría con el principio de no discriminación y de neutralidad tecnológica, pilares elementales de Internet y del comercio electrónico. En tal sentido, una premisa básica a tener en cuenta consiste en evitar asimetrías sin fundamento jurídico real entre los criterios aplicables a las relaciones jurídicas tradicionales y a las que se desarrollan online.

El Derecho Internacional Privado puede jugar un rol destacado, en tanto y en cuanto este medio es eminentemente internacional y tiene la suficiente virtualidad para permitir un crecimiento exponencial de las relaciones jurídicas transfronterizas entre particulares.

Nuestra disciplina cuenta con una pluralidad de fuentes, de origen nacional, internacional, regional, y transnacional, de carácter vinculante (hard law) y no vinculante (soft law), que de modo coordinado y coherente están suficientemente capacitadas para dar respuestas idóneas a los problemas que se presentan en el ciberespacio. Asimismo, el pluralismo metodológico es una característica del DIPr actual y contribuye a modelar mejor las respuestas jurídicas, ya sea a través de reglas de conflicto, de normas de derecho uniforme, y cuando sea necesario, de normas de policía.

La co-regulación en el Derecho Internacional Privado es factible a través de la labor conjunta de los Estados, de las organizaciones internacionales gubernamentales y no gubernamentales e incluso, de los agentes privados que tejen y destejen las reglas que entienden son las más apropiadas para regir sus negocios.

En el área de libre disponibilidad de los sujetos privados, la autonomía de la voluntad, las reglas de soft law, la lex mercatoria y su nueva versión como lex electrónica juegan un rol central.

Sin embargo, los Estados tienen aún un papel preponderante. Existen intereses públicos, valores, bienes jurídicos tutelables de los que aquellos no se pueden desentender. Para ello, las normas jurídicas clásicas, de carácter obligatorio, preferentemente de fuente convencional y subsidiariamente, de índole interna, respaldadas en cualquier caso por el monopolio de la fuerza pública, resultan de toda necesidad y eficacia. 
Por otro lado, en el ámbito jurisdiccional, los criterios que determinen la competencia de los tribunales nacionales deben garantizar una tutela judicial efectiva de todos los operadores y usuarios de Internet, a través de la amplia disponibilidad de foros razonables que presenten contactos suficientes y concretos con el caso.

A su turno, las nuevas tecnologías de la información bien pueden aprovecharse útilmente en los procedimientos judiciales y arbitrales tradicionales, a los fines de alcanzar una cooperación jurídica internacional eficaz. Asimismo, los mecanismos de solución de controversias online, principalmente en el ámbito de las cuestiones patrimoniales son una alternativa expedita para brindar soluciones a los justiciables.

En suma, la complejidad de la sociedad de la información impone, exige soluciones renovadas, plurales, a través de una multiplicidad de fuentes estatales y extraestatales, en donde actores públicos y privados deben cumplir sus respectivos roles para el logro de una óptima gobernanza global.

\section{Bibliografía}

Albornoz Barriento, J. y Magdic, M. (2013). Marco jurídico de la utilización de videoconferencia en materia penal. Revista Chilena de Derecho y Tecnología, vol. 2, No 1 (pp. 229-260). DOI 10.5354/0719-2584.2013.27012 [Fecha de consulta: 22/01/2020].

Albornoz, M. M. y Paredes, S. (2019). Nuevo Tratado de Medellín: la tecnología de la información al servicio de la cooperación internacional. Derecho en Acción, Centro de Investigación y Docencia Económicas (CIDE). Recuperado de http://derechoenaccion.cide.edu/nuevo-tratado-de-medellin-la-tecnologia-dela-informacion-al-servicio-de-la-cooperacion-internacional/ [Fecha de consulta: $22 / 01 / 2020]$.

Burnstein, M. (1995). Conflicts on the net: choice of law in transnational cyberspace. Vanderbilt Journal of Transnational Law, № 29 (pp. 75-87).

Calvo Caravaca, A. L. y Carrascosa González, J. (2001a). Conflictos de leyes y conflictos de jurisdicciones en Internet. Madrid: Ed. Colex.

Calvo Caravaca, A. L. y Carrascosa González, J. (2001b). Problemas de extraterritorialidad en la contratación electrónica. En J. A. Echebarría Sáenz (coord.), $E l$ comercio electrónico (pp. 145-217). Madrid: Edisofer.

Cerdeira, J. J. (2017). Buenas prácticas y nuevas tecnologías en la cooperación penal en el MERCOSUR. Revista de la Secretaría del Tribunal Permanente de Revisión (STPR), año 5, No 10 (pp. 117 - 131). DOI 10.16890/rstpr.a5.n10.p117. Recuperado 
INCIDENCIAS DE LAS NUEVAS TECNOLOgÍAS EN EL DERECHo INTERNACIONAL PRIVAdo

- LUCIANA B. SCOTTI (PP. 409-442)

de http://www.revistastpr.com/index.php/rstpr/article/view/263/364 [Fecha de consulta: 22/01/2020].

De Miguel Asensio, P. A. (2001). Derecho Privado de Internet. Madrid: Civitas.

Draetta, U. (2005). Internet et commerce électronique en droit international des affaires. Recueil des cours, Vol. 314 (pp. 9-232).

Dreyzin de Klor, A. (2005). Derecho Aplicable al Comercio Electrónico. Revista Seqüência, No 50 (pp. 273-299).

Dreyzin de Klor, A. (2010). La cooperación jurídica internacional: instrumento imprescindible para la integración. En A. Oropeza García (coord.), Latinoamérica frente al espejo de su integración (1810-2010) (pp. 263-284). México: UNAM. Recuperado de http://biblio.juridicas.unam.mx/libros/6/2923/19.pdf [Fecha de consulta: $22 / 01 / 2020]$.

Fauvarque - Cosson, B. (2001). Le droit international privé classique à l'épreuve des réseaux. Coloque Droit de l'Internet: approches européennes et internationales, 19 y 20 de noviembre (pp. 2-3). Recuperado de http://droit-internet-2001.univparis1.fr/vf/index.html [Fecha de consulta: 22/01/2020].

Fernández Arroyo, D. P. (2008). Aspectos esenciales de la competencia judicial internacional en vistas de su reglamentación interamericana. En E. Picand Albónico y H. Llanos Mansilla (coords.), Estudios de derecho internacional: libro homenaje al profesor Santiago Benadava (pp. 293-326), vol. 2. Santiago de Chile: Librotecnia. Recuperado de http://www.oas.org/dil/esp/293-326\%20Diego\%20 Fern\%C3\%A1ndez\%20A.\%20def.BIS.pdf [Fecha de consulta: 22/01/2020].

Forcada Miranda, F. J. (2017). Comunicaciones Judiciales Directas y Cooperación Jurídica Internacional. Una Propuesta de Guía Práctica Española para casos específicos a la luz de los Trabajos de la Conferencia de La Haya de Derecho Internacional Privado (Tesis doctoral). Universidad Nacional de Educación a Distancia (UNED). Madrid. Recuperado de http://e-spacio.uned.es/fez/eserv/ tesisuned:ED-Pg-DeryCSoc-Fjforcada/FORCADA_MIRANDA_FranciscoJavier_ tesis.pdf [Fecha de consulta: 22/01/2020].

Goicoechea, I. (2016). Nuevos desarrollos en la cooperación jurídica internacional en materia civil y comercial. Revista de la Secretaria del Tribunal Permanente de Revisión (STPR), año 4, № 7 (pp. 127-151). DOI: http://dx.doi.org/10.16890/ rstpr.a4.n7.p127. Recuperado de http://www.revistastpr.com/index.php/rstpr/ article/view/191/227 [Fecha de consulta: 22/01/2020]. 
González Campos, J. D. (2000). Diversification, spécialisation, flexibilisation et matérialisation des règles de droit international privé. Recueil des cours, vol. 287 (pp. 9-426).

Huet, J. (2001). Le droit applicable dans les réseaux numériques. Coloque Droit de l'Internet: approches européennes et internationales, 19 y 20 de noviembre (pp. 1-2). Recuperado de http://droit-internet-2001.univ-paris1.fr/vf/index.html [Fecha de consulta: 22/01/2020].

Lorente Martínez, I. (2012). Lugar del hecho dañoso y obligaciones extracontractuales. La sentencia del TJUE de 25 octubre 2011 y el coste de la litigación internacional en Internet. Cuadernos de Derecho Transnacional, vol. 4, № 1 (pp. 277-301). Recuperado de http://e-revistas.uc3m.es/index.php/CDT/article/ view/1474/614 [Fecha de consulta: 22/01/2020].

Lorenzetti, R. (2001). Comercio electrónico. Buenos Aires: Abeledo Perrot.

Madrid Martínez, C. (2019). COMJIB: Tratado relativo a la Transmisión Electrónica de Solicitudes de Cooperación Jurídica Internacional entre Autoridades Centrales. Cartas Blogatorias. Recuperado de https://cartasblogatorias.com/tag/tratado-relativo-a-la-transmision-electronica-de-solicitudes-de-cooperacion-juridica-internacional-entre-autoridades-centrales/ [Fecha de consulta: 22/01/2020].

Matteo, V. (2003). Internacionalidad de los contratos celebrados por medios electrónicos y determinación de la ley aplicable. En S. Rippe; I. Creimer y otros, Comercio electrónico. Análisis jurídico multidisciplinario (pp. 174-191). Buenos Aires: Bdef.

Moreno Rodríguez, J. A. (2013). Derecho aplicable y arbitraje internacional. Asunción: CEDEP.

Muir Watt, H. (2004). Aspects économiques du droit international privé: (réflexions sur l'impact de la globalisation économique sur les fondements des conflits de lois et de juridictions). Recueil des cours, vol. 307 (pp. 25-384).

Oyarzábal, M. (2003). La ley aplicable a los contratos en el ciberespacio transnacional. El Derecho, No 201 (pp. 709-724).

Oyarzábal, M. (2006). La ley aplicable a los contratos en el ciberespacio transnacional. Revista DeCITA. Derecho del comercio internacional. Temas y actualidades Internet, comercio electrónico y sociedad de la información, No 5/6.2006 (pp. 130-131).

Pamboukis, C. P. (2008). Droit international privé holistique: droit uniforme et droit international privé. Recueil des cours, vol. 330 (pp. 9-474). 
INCIDENCIAS DE LAS NUEVAS TECNOLOgÍAS EN EL DERECHo INTERNACIONAL PRIVAdo

- LUCIANA B. SCOTTI (PP. 409-442)

Santos Belandro, R. B. (2013). Territorio, Frontera, Soberanía y Espacios: Cuatro conceptos que tensionan al Derecho Internacional Privado actual. Revista de Derecho Público, año 22, oo 43 (pp. 75-110).

Scotti, L. B. (2012). Contratos electrónicos. Un estudio desde el Derecho Internacional Privado argentino. Buenos Aires: EUDEBA.

Scotti, L. B. (2016). Derecho Internacional Privado. Globalización e Internet. México: Porrúa.

Scotti, L. B. (2019). Avances con miras a la protección de los consumidores en el Mercosur. Revista Anales de la Facultad de Ciencias Jurídicas y Sociales de la Universidad Nacional de La Plata, año 16, No 49/2019 (pp. 295-329). DOI: https:// doi.org/10.24215/25916386e013. Recuperado de https://revistas.unlp.edu.ar/RevistaAnalesJursoc/issue/view/662 [Fecha de consulta: 22/01/2020].

Smith, B. L. (2000). The Third Industrial Revolution: law and policy for the Internet. Recueil des Cours, vol. 282 (pp. 231-464).

Tellechea Bergman, E. (2002). La dimensión judicial del caso privado internacional en el ámbito regional. Montevideo: FCU.

Tellechea Bergman, E. (2009). Balance y perspectivas de la cooperación jurisdiccional internacional en el ámbito de Mercosur. Microjuris, MJ-DOC-4336AR | MJD4336. Recuperado de http://ar.microjuris.com/ [Fecha de consulta: $22 / 01 / 2020]$.

Tirado Estrada, J. J. (2017). Videoconferencia, cooperación judicial internacional y debido proceso. Revista de la Secretaria del Tribunal Permanente de Revisión (STPR), año 5, No 10 (pp. 153-173). DOI: 10.16890/rstpr.a5.n10.p153. Recuperado de http://www.revistastpr.com/index.php/rstpr/article/view/262/366 [Fecha de consulta: 22/01/2020].

Uriondo de Martinoli, A. (2012). Lesión de los derechos de la personalidad a través de internet. Revista de la Facultad, vol. III, No 2, Nueva Serie II (pp. 155-175). Recuperado de http://revistas.unc.edu.ar/index.php/refade/article/viewFile/5997/7070 [Fecha de consulta: 22/01/2020].

Véscovi, E. (2019). El Derecho de acceso a la Justicia y el Derecho Internacional Privado. Relato de la Sección de Derecho Internacional Privado del XXXI Congreso Argentino de Derecho Internacional, Córdoba, septiembre. Recuperado de https:// aadi.org.ar/ [Fecha de consulta: 22/01/2020]. 


\section{Documentos consultados}

Asociación Americana de Derecho Internacional Privado. Principios ASADIP sobre el Acceso Transnacional a la Justicia (Principios TRANSJUS), aprobados en Buenos Aires, el 12 de noviembre de 2016. Recuperado de http://www.asadip.org/ v2/wp-content/uploads/2018/08/ASADIP-TRANSJUS-ES-FINAL18.pdf [Fecha de consulta: $22 / 01 / 2020]$

Comisión de las Naciones Unidas para el Derecho Mercantil Internacional (CNUDMI). Notas Técnicas sobre la Solución de Controversias en Línea, 2016. Recuperado de https://uncitral.un.org/sites/uncitral.un.org/files/media-documents/ uncitral/es/v1700385_spanish_technical_notes_on_odr.pdf [Fecha de consulta: $22 / 01 / 2020]$.

Conferencia de La Haya de Derecho Internacional Privado. Conclusiones y Recomendaciones adoptadas por la Comisión Especial sobre el funcionamiento práctico de los Convenios sobre la Apostilla, la Obtención de pruebas y la Notificación, 28 de octubre a 4 de noviembre de 2003. Recuperado de https://assets.hcch.net/ upload/wop/lse_concl_s.pdf [Fecha de consulta: 22/01/2020].

Conferencia de La Haya de Derecho Internacional Privado. Conclusiones y Recomendaciones adoptadas por la Comisión especial de 2009 relativa al funcionamiento práctico de los Convenios de La Haya sobre Apostilla, Obtención de pruebas, Notificación y Acceso a la justicia. Recuperado de https://assets.hcch.net/upload/ wop/jac_concl_s.pdf [Fecha de consulta:22/01/2020].

Conferencia de La Haya de Derecho Internacional Privado. Conclusiones y Recomendaciones de la Comisión Especial sobre el funcionamiento práctico de los Convenios de La Haya sobre Notificación, Obtención de Pruebas y Acceso a la Justicia, 20 a 23 de mayo de 2014. Recuperado de https://assets.hcch.net/docs/22f3f9dbb2bb-4256-95cb-65c4cbb65ad7.pdf [Fecha de consulta: 22/01/2020].

Conferencia de La Haya de Derecho Internacional Privado. Proyecto de documento para informar a abogados yjueces sobre comunicacionesjudiciales directas en casos especificos en el marco de la Red Internacional de Jueces de la Haya, Documento preliminar $N^{o} 5$ de julio de 2017. Séptima reunión de la Comisión Especial sobre el funcionamiento práctico del Convenio de 1980 sobre Sustracción Internacional de Menores y del Convenio de 1996 sobre Protección de Niños, octubre de 2017. Recuperado de https://assets.hcch.net/docs/f4db8735-14b6-430c-8886-112d0e4eb5f2.pdf [Fecha de consulta: 22/01/2020].

Conferencia de La Haya de Derecho Internacional Privado. Séptima reunión de la Comisión Especial sobre el funcionamiento práctico del Convenio de 1980 sobre 
Sustracción Internacional de Menores y del Convenio de 1996 sobre Protección de Niños, 10 al 17 de octubre de 2017. Recuperado de https://assets.hcch.net/docs/ b50c61b7-50a2-495c-b004-36e9000646df.pdf [Fecha de consulta: 22/01/2020].

Reunión Interamericana de Jueces y Autoridades Centrales de la Red Internacional de La Haya sobre Sustracción Internacional de Menores, México, 23 a 25 de febrero de 2011. Recuperado de https://www.hcch.net/es/news-archive/ details/?varevent=217 [Fecha de consulta: 22/01/2020].

Fecha de recepción: 05-02-2020

Fecha de aceptación: 24-06-2020 
